\title{
Microscope slide electrophoresis of serum lipoproteins in agarose gel
}

\author{
M. C. ELPHICK \\ From the Department of Paediatric Surgery, Institute of Child Health, London
}

SYNOPSIS An ultramicro electrophoretic technique for the separation of serum lipoproteins is described using agarose gel on microscope slides.

The interaction between the agarose gel and lipoproteins has been reduced and the separation between $\beta$ - and pre- $\beta$-lipoproteins has been improved over existing methods. A semiquantitative assay of the lipoproteins can be done in a densitometer. It is suggested that the interaction between agarose gel and lipoproteins, which, without albumin in the system, results in distortion of the lipoprotein bands, may be mediated by free fatty acids.

Several methods have been developed for separating serum lipoproteins by electrophoresis in agarose gel, (Kalab and Martin, 1968; McGlashan and Pilkington, 1968; Noble, 1968; Rapp and Kahlke, 1968). These methods give better separation and quantitation of the different lipoproteins than existing methods using paper electrophoresis. The method of Noble (1968) has a distinct advantage over the other methods in that the interaction between gel and lipoproteins (Wieme, 1965) has been reduced by incorporating albumin in the agarose. In the technique of Kalab and Martin (1968) only small quantities of materials are required and electrophoresis can be done on microscope slides which, after drying and staining, can be scanned and the quantities of the various lipoproteins measured. This method was found to suffer from crescent formation of the lipoprotein bands and the gel was found to be dilute and difficult to handle, but the staining technique was good. The methods of Rapp and Kahlke (1968), McGlashan and Pilkington (1968), and Noble (1968) require relatively large quantities of materials and complex methods for applying the samples. The following is a description of a simple method modified so as to enable the separation of serum lipoproteins in agarose gel on microscope slides using samples of $2 \mu \mathrm{l}$ only. There is no crescent formation of the bands and after drying and staining the slides can be scanned in a densitometer for quantitation.

\section{Apparatus}

The tank employed for electrophoresis was similar to that described by Wieme (1959) except that Received for publication 25 June 1970. petroleum ether was not used as a coolant. Glass templates were used for setting the gel and were made from microscope slides, $7.5 \mathrm{~cm} \times 5 \mathrm{~cm} \times$ $1.5 \mathrm{~mm}$. Two strips of glass $1 \mathrm{~mm}$ thick and $6 \mathrm{~mm}$ wide were fixed longitudinally to the top surface of one of these slides using epoxy resin. Another microscope slide of similar dimensions could then be placed on top of this so forming a sandwich containing an empty space $3.8 \mathrm{~cm} \times 7.5 \mathrm{~cm} \times$ $1.0 \mathrm{~mm}$ in size. The template could be placed in a shallow dish $5.5 \mathrm{~cm} \times 8 \mathrm{~cm}$ (Fig. 1). For cutting the sample grooves a razor blade was prepared with three blades $6 \mathrm{~mm}$ long and each $6 \mathrm{~mm}$ apart.

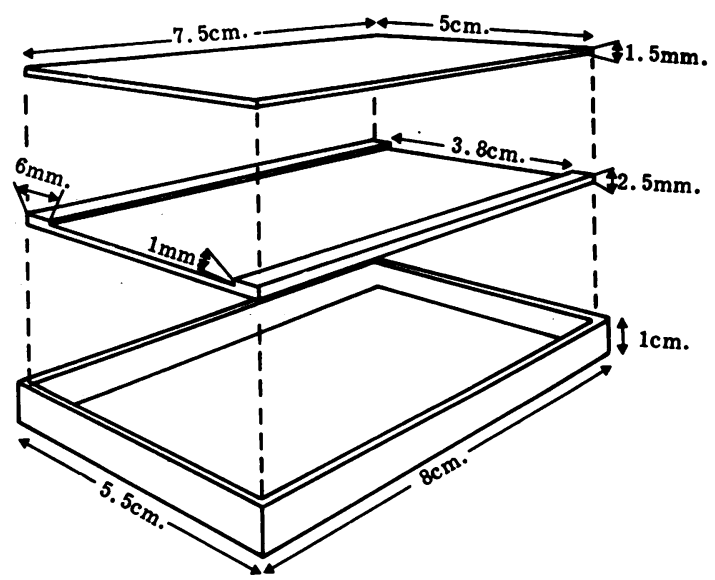

Fig. 1. The glass template and dish used in the preparation of the gel strip. 


\section{Method}

BUFFER SOLUTION (0.05 M BARBITONE BUFFER pH 8.20)

Of sodium barbitone (sodium 5,5-diethylbarbiturate), $20.6 \mathrm{~g}$ was weighed out and made up to 1 litre with distilled water; $769 \mathrm{ml}$ of this solution was made up to 1 litre with $0 \cdot 1 \mathrm{~N} \mathrm{HCl}$ and then diluted to 2 litres with more distilled water. The $p \mathrm{H}$ was checked and adjusted if necessary.

\section{ALBUMIN SOLUTION}

Five $\mathrm{g}$ of bovine albumin, Cohn fraction V (KochLight Laboratories Ltd., Buckinghamshire, England) was dissolved in and made up to $50 \mathrm{ml}$ with the barbitone buffer.

PREPARATION OF THE AGAROSE SOLUTION Agarose, $0.8 \mathrm{~g}$ (sulphate content less than $0.1 \%$ ) (obtained from Koch-Light Laboratories Ltd., or from Seravac Laboratories Ltd., Berkshire, England) was weighed out and made up to about $90 \mathrm{ml}$ with barbitone buffer in a $100 \mathrm{ml}$ volumetric flask. The flask was heated in a water bath and boiled for 30 minutes with occasional agitation. After this time the solution was quite clear. The flask and contents were then transferred to a second water bath at $50^{\circ} \mathrm{C}$ and the contents cooled to that temperature. Then $5 \mathrm{ml}$ of the albumin solution was added and the solution made up to $100 \mathrm{ml}$ with buffer and then mixed. The agarose/albumin solution was kept at $50^{\circ} \mathrm{C}$ until used.

SETTING OF GEL IN THE TEMPLATE

The glass template was placed edge side up in the shallow dish, then about $20 \mathrm{ml}$ of the agarose/ albumin solution was rapidly poured into the dish and the top microscope slide edged into position above the bottom plate, care being taken not to include any air bubbles. The gel was then allowed to set. Another portion of the agarose solution was used to prepare the electrode blocks.

\section{Collection of Blood and Application of Sample}

Serum was obtained by centrifugation of clotted blood and was stored for up to 24 hours at $4{ }^{\circ} \mathrm{C}$. Any chylomicrons were removed.

The gelled plate was removed from the dish and the excess solid agarose cut from round the edges. The remaining thin layer of gel between the plates was removed and placed onto another microscope slide of suitable size. Three slits were then cut in this about $10 \mathrm{~mm}$ from one end using the razor blade. The slits were dried with pieces of filter paper and $2 \mu$ l of serum was pipetted into the two outer slits using Microcaps(Drummond Scientific Co, Brooma焗, $\mathrm{Pa}, \mathrm{USA})$. Two $\mu$ l of human albumin solution $(4 \%$ Cohn fraction $\mathrm{V}$ prestained with bromophenol blu的) was pipetted into the centre slit. The slide was then inverted and placed on the agarose blocks in the electrophoresis tank. The electrode chambers we filled with the barbitone buffer and the current w switched on. The slits containing the samples were nearest to the cathode chamber. The current wâs about 8-10 $\mathrm{mA}$ and the voltage over the plate abogt $35 \mathrm{~V}$ (6 volts $/ \mathrm{cm})$. Electrophoresis was discontinued when the stained albumin had moved about $5 \mathrm{crm}$ which took between two and two and a half houis.

FIXING AND DRYING

in

When the electrophoresis was stopped the gel was placed in a solution of $2.5 \%$ trichloracetic acid for 45 minutes. After this the gel was washed in distillee water for 20 minutes. It was then taken from the water on a glass plate, the excess water was removed with filter paper, and the gel was sliced down the middle using a razor blade. The two halves of gel were layered onto two scrupulously clean microscope slides, $7.5 \mathrm{~cm} \times 2.5 \mathrm{~cm}$, and carefully drie using a hair drier. The gel was found to adhere wetl to the glass slides.

STAINING

In order to stain all the slides uniformly the staining procedure was standardized as follows:

Thirty-two mg of Fat Red 7B (Hopkins and Williams Ltd, Essex, England) and $16 \mathrm{mg}$ of $\mathrm{O}$ Red 0 (British Drug Houses Ltd, Poole, England) were weighed out and refluxed with $100 \mathrm{ml}$ of 800 analytical grade methanol for 15 minutes. After this time the mixture was cooled, filtered, and 40 rol of the filtrate immediately used for staining in open dish $10 \mathrm{~cm}$ wide and $15 \mathrm{~cm}$ long. The slides were placed gel side up in this dish which was kept at exactly $20^{\circ} \mathrm{C}$. After staining for two hours the slides were removed and allowed to dry.

\section{Quantitation}

Although some doubt exists as to the uniformity with which different lipoproteins take up stai densitometric scanning can provide good semfo quantitative data.

\section{Results}

Stained slides were scanned in a Chromoscan (Joyce Loebl Instruments Ltd) at a wavelength of $520 \mathrm{~m} \mu$ and the area beneath each peak was determined. Figure shows a typical unretouched tracing of a separation done on a sample of serum from a fasting healthy 


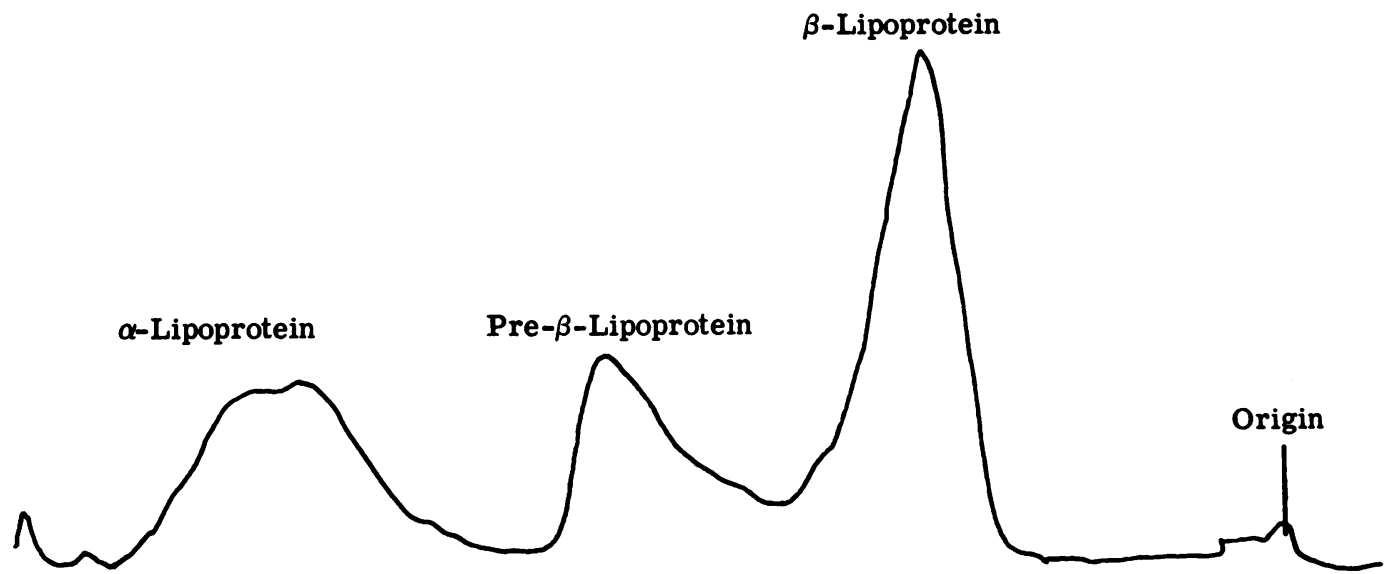

Fig. 2. An unretouched scan of a separation done on a sample of serum from a healthy 51-year-old fasting male.

51-year-old man. The separation between the three major lipoproteins was excellent and there was no crescent formation of the bands. Reproducibility of the method was also found to be good provided that the staining procedure was strictly adhered to. Table I shows four different values obtained for the areas beneath each lipoprotein peak separated from serum obtained from a 26 -year-old fasting man. The same serum sample was used but the final slides were stained separately.

It is unfortunate that the inclusion of albumin in the gel does not allow staining of the slides for protein.

\begin{tabular}{llll}
\hline & $\beta$-Lipoprotein & Pre- $\beta$-lipoprotein & $\alpha$-Lipoprotein \\
\hline 1 & 113 & 68 & 110 \\
2 & 125 & 65 & 112 \\
3 & 128 & 70 & 81 \\
4 & 130 & 68 & 100 \\
\hline
\end{tabular}

Table I Four values for areas beneath each lipoprotein peak obtained for the same sample of serum stained on different occasions

\section{Reaction between Lipoproteins and Agarose Gel}

Pure agarose is an unchanged linear galactose polymer (Araki, 1956), but after its purification some residual sulphate and other charged groups remain and these are thought to react with serum lipoproteins causing the phenomenon of 'self slowing' (Wieme, 1965). It was noticed, however, that when albumin was included in the system the mobility of the lipoproteins, especially the $\beta$ - and pre- $\beta$-bands, was slower than when albumin was omitted. It would therefore seem that the reaction with the gel results in increased mobility. Moreover, in preliminary experiments it was found that if a small amount of ordinary soap or of sodium linoleate $(0.1 \mathrm{~m}$-equiv/l) was added to the buffer and the gel without albumin then the mobility of the lipoproteins was greatly increased; indeed, the rate of migration of the bands was greater than that of an albumin marker. As a point of interest this could form the basis of a method for preparing pure lipoproteins, but unfortunately the bands were diffuse and overlapping. When, however, albumin was incorporated into the gel the rate of migration was unaltered after soap or sodium linoleate had been added. Albumin is well known to have strong binding sites for fatty acids and it is possible that it prevents the reaction between the lipoproteins and the gel by virtue of this property. It is therefore a possibility that the reaction between the gel and lipoproteins is mediated by free fatty acids already present in serum.

I am grateful to Mr D. R. Morgan for his technical assistance.

\section{References}

Araki, C. (1956). Structure of the agarose constituent of agar-agar. Bull. chem. Soc. Japan, 29, 543.

Kalab, M., and Martin, W. G. (1968). Electrophoresis of pig serum lipoproteins in agarose gel. Analyt. Biochem., 24, 218-225.

McGlashan, D. A. K., and Pilkington, T. R. E. (1968). A method of lipoprotein electrophoresis using agarose gel. Clin. chim. Acta, 22, 646-647.

Noble, R. P. (1968). Electrophoretic separation of plasma lipoproteins in agarose gel. J. Lipid Res., 9, 693-700.

Rapp, W., and Kahlke, W. (1968). Lipoprotein-elektrophorese in agarose gel. Clin. chim. Acta, 19, 493-498.

Wieme, R. J. (1965). Agar Gel Electrophoresis, pp. 118-120. Elsevier, Amsterdam.

Wieme, R. J. (1959). An improved technique of agar-gel electrophoresis on microscope slides. Clin. chim. Acta, 4, 317-321. 